\title{
КОНТРОЛЛИНГ ПРОМЫШЛЕННЫХ ПРЕДПРИЯТИЙ
}

\author{
В.А. ТЕЛЕГИН \\ к.П.н., доц. каф. МТСС \\ ФГБОУ ВПО «СПбГУСЭ»
}

\begin{abstract}
Аннотация:
Статья посвящена развитию системы контроллинга на промышленных предприятиях.

В ней представлены различные концептуальные представления о контроллинге, с анализом их достоинств и недостатков.

Также автором рассмотрены концептуальные аспекты стратегического и текущего планирования организационных процессов в системе контроллинга, сделан анализ компонентов системы контроллинга на промышленном предприятии, предложен перечень показателей, который необходимо использовать в системе контроллинга промышленных предприятий.

Ключевые слова: контроллинг, стратегическое планирование, текущее планирование, промышленное предприятие.
\end{abstract}

\section{ВВЕДЕНИЕ}

В современных условиях развития российской экономики эффективность работы предприятий все больше зависит от применяемых технологий и методов контроля. Ускорение темпов научно-технического прогресса, глобализация политических, экономических и производственно-хозяйственных связей, усиление конкуренции выдвигают новые требования к системе контроля на промышленных предприятиях.

В связи с этим появляется объективная необходимость управляемости таких систем с помощью новых методов управления, соответствующих усложнению внешней и внутренней среды предприятий. В этих условиях необходимым становится использование контроллинга как важного элемента управления, обеспечивающего информационно-аналитическую поддержку руководству при принятии управленческих решений.

Поэтому, большое внимание в настоящее время уделяется вопросам построения и внедрения контроллинга как структурной составляющей процесса управления. Дефицит специалистов в данной области и отсутствие нормативной базы, регулирующей организацию контроллинга, существенно затрудняют создание эффективной системы контроллинга на предприятии.

Система контроллинга обеспечивает системный сбор, обработку и анализ информации по всем подразделениям компании, определяет ее соответствие принятой стратегии развития. На этой основе существенно улучшается качество управления. Поэтому, многие ученые уделяют большое внимание исследованию контроллинга. Среди зарубежных авторов это: Блауг М., Буайе Р., Бью- 
кенен Дж., Вагенхофер А., Вайзенберг Б., Друкер П., Друри К., Зервас А., Каплан Р., Хорват П., Хорнгрен Ч., Шерм Э., Эверт Р., Эрман Х., и др.

Значительный вклад в адаптацию теории контроллинга к современным условиям российской экономики сделали: Ананькина Е.А., Анискин Ю.П., Данилочкина Н.Г., Дедов О.А., Зайцев С.Н., Ивашкевич В.Б, Малышева Л.А., Николаева О.Е., Оленев, Н.И., Плеханова А.Ф., Уткин Э.А., Фалько С.Г. и др.

При этом следует отметить, что в современном научном арсенале накопилось множество определений контроллинга, каждое из которых отражает ту или иную концепцию в диапазоне от узкого понимания на уровне варианта управленческого учета или инструмента управления до признания его философией менеджмента [ЦИРЭ].

Во-первых, контроллинг рассматривается как функция менеджмента, задачей которого является его методическая поддержка в процессе принятия управленческих решений при разработке систем планирования, стимулирования и учета.

Во-вторых, контроллинг рассматривается как интегрированная система, задачами которого является обеспечение координации функционирования подразделений и служб предприятия, поддержание баланса интересов участников производственного процесса, управление системой целей и соблюдение принципа композиции в развитии организации.

В-третьих, контроллинг понимается как информационная система, обеспечивающая формирование информационной базы при внедрении модели управления предприятием, ориентированной на результат для его развития за счет оптимизации финансового результата в рамках реализации социальных целей.

«Системой управления» считают контроллинг Ивашкевич В.Б., Воронин В.П., Королев А.Ю., Майер Р., Майер Э., Никонова Т.В., Осорина Е., Петрусевич Н. и др.

Однако, анализ научных работ, посвященных концепциям и методам создания системы контроллинга, показал, что теория организации контроллинга на сегодняшний день разработана недостаточно. В отечественных работах, посвященных контроллингу, рассматриваются преимущественно вопросы концептуального характера, анализируется роль контроллинга в принятии управленческих решений, но остается без внимания сам процесс формирования сисетмы контроллинга.

Большинство исследователей рассматривают понятие контроллинга либо как синоним понятия «управленческий учет», а систему контроллинга как интегрированную планово-учетную подсистему менеджмента предприятия, альтернативной или дополняющей подсистемы бухгалтерского учета и планирования, либо как современную модель информационной системы, либо подменяют понятие «менеджмент» понятием «контроллинг» наделяя его функциями, связанными с работой планового, финансового отделов предприятия. 


\section{РЕЗУЛЬТАТЫ И ИХ ОБСУЖДЕНИЕ}

По нашему мнению, исходя из лингвистических особенностей английского языка следует разделить понятия «контроль» и «контроллинг». Понятие «контроль» применимо к техническим, математическим, финансовым системам и предполагает применение системы точных измерений выполняемых работ или расчетов в определенном временном интервале. Понятие «контроллинг» следует применять по отношению к сложным системам, состоящим из разноуровневых элементов, включающим в себя человека и предполагающим качественный и количественный анализ длительных процессов, например промышленное предприятие.

Таким образом, контроллинг следует рассматривать как систему управления, направленную на координацию и интеграцию всех функций менеджмента для формирования и устойчивого развития конкурентных преимуществ организации. Контроллинг позволяет выявить и исследовать тенденции развития предприятия к намеченной стратегической цели с помощью текущих инструментов управления.

При этом следует отметить, что в системе управления предприятием контроллинг может выполнять интеграционную функцию, объединяя планирование, учет, контроль и анализ в единую самоуправляемую систему, в которой четко определяются цели предприятия, принципы управления и способы их реализации.

В экономическом контексте контроллинг, обеспечивая стабильность бизнеса и его финансов, выявляя внутренние резервы и риски является фактором обеспечения устойчивости и конкурентоспособности предприятия. Оптимизируя модель управления промышленным предприятием с учетом его специфики, контроллинг позволяет четко соблюдать принцип целеполагания и принцип соответствия.

В контексте управления контроллинг способствует системному управлению предприятием, так как связывает информационные потоки в ходе реализации учетной, аналитической и контрольной функций управления, трансформируя их в основания для принятия преобразующих решений.

Это обуславливает необходимость разработки механизма организации контроллинга, позволяющего комплексно подойти к вопросу построения системы контроллинга на промышленном предприятии [1].

Структурно-функциональный подход к формированию и развитию механизма производственного контроллинга предполагает диверсификацию функций и технологий менеджмента в контексте повышения результативности прогнозирования, стратегического и оперативного планирования, регулирования, стимулирования, корректировки отдельных целей и показателей производственного развития в связи с изменением внешней среды, конъюнктуры рынка и внутренних условий осуществления хозяйственной деятельности промышленных предприятий, а также информационного обеспечения функционирования всех структурных подразделений данных предприятий. Данный подход предполагает: 
- интегрированное взаимодействие всех служб и подразделений предприятия;

- координацию мер по достижению стратегических и оперативных целей предприятия;

- информационную поддержку менеджмента.

При этом контроллинг как система обеспечения инновационных преобразований бизнес-процессов, продукции, организационных структур должен отвечать следующим требованиям:

- использование ограниченного объема показателей;

- обеспечение многофункциональной оценки деятельности промышленного предприятия; динамизм и перспективность индикаторов;

- сопоставимость параметров во временных интервалах, межотраслевых и других видах сравнений [2].

При этом контроллинг может быть реализован на промышленных предприятиях в двух направлениях: стратегический контроллинг и текущий контроллинг.

Целью стратегического контроллинга является обеспечение достижения намеченных целей развития и формирования устойчивых конкурентных преимуществ предприятия.

Задачами развития этого направления контроллинга являются:

- анализ внешней и внутренней среды;

- формирование качественных целей;

- разработка показателей, определяющих конкурентный статус организации;

- определение «слабых сторон» в деятельности предприятия;

- разработка системы многоуровневого контроля и принятия решений;

- создание системы сравнительных характеристик плановых и фактических значений подконтрольных показателей с выявлением причин, источника и последствий отклонений фактических показателей от плановых;

- анализ влияния отклонений в выполнении плановых показателей на реализацию стратегий и сценариев организационного развития, рыночного поведения;

- принятие управленческих решений и изменение стратегий.

Целью текущего контроллинга является обеспечение прибыльности и ликвидности предприятия для обеспечения устойчивого развития его конкурентных преимуществ.

Задачами текущего контроллинга являются:

- определение влияния факторов внешней и внутренней среды на текущие цели предприятия;

- разработка и текущее планирование количественных целевых показателей в соответствии со стратегическими планами и сценариями в разрезе центров ответственности на короткий период;

- создание системы текущего управления, обеспечивающей сравнение плановых (нормативных) и текущих (фактических) показателей подконтрольных 
результатов и затрат с целью выявления причин, источников и последствий отклонений, оказывающих влияние на целевые показатели, определяющие конкурентные преимущества в краткосрочном периоде;

- принятие управленческих решений.

Система текущего контроллинга промышленного предприятия включает в себя:

- Подсистему выбора оптимального ассортимента производимой продукции с применением матрицы BCG.

- Подсистема формирования контрольных показателей.

- Подсистема технического контроля с применением измерительных приборов, специальных технических средств, экономико-математических моделей и прикладных экономико-математических программ.

- $\quad$ Подсистема принятия решений на этапе текущего управления.

Связь стратегического планирования и текущего планирования в процессе выбора оптимального ассортимента производимой продукции приведена на рис. 1

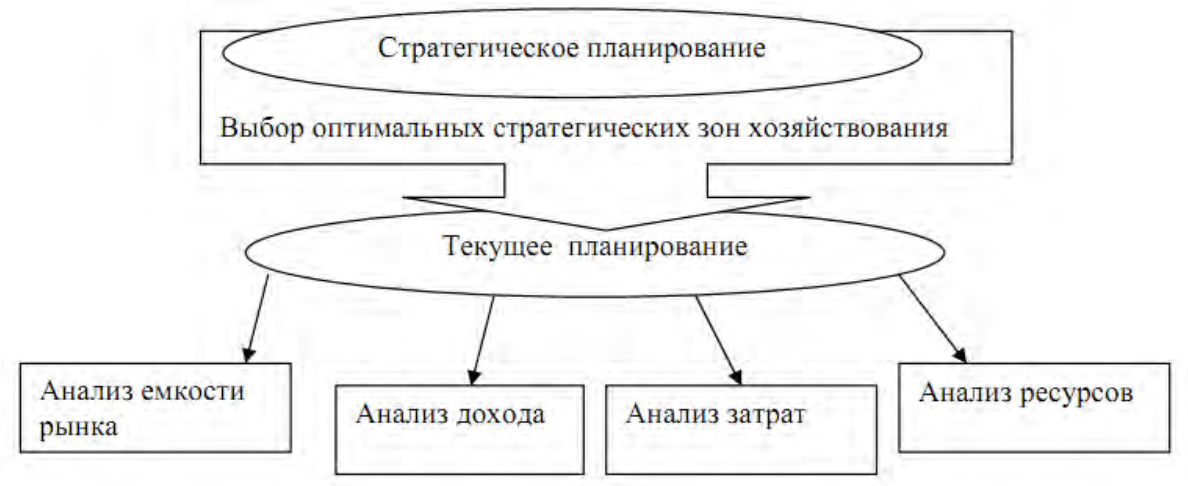

Рис. 1 - Связь стратегического и текущего планирования

При этом планирование предполагает мониторинг и изменение ресурсного обеспечения деятельности предприятия, а именно:

-изменение уровня запасов;

- варьирование численности работников в зависимости от изменения объемов производства от изменения спроса на продукцию;

- варьирование темпов производства;

- субподряд;

- использование временных работников, аутсорсинга и аутстаффинга;

- изменение спроса с помощью рекламы, варьирования цен и использования каналов продвижения продаж;

- задержка заявок в период максимального спроса;

- сочетание всесезонных продуктов и сервиса.

При этом область применения контроллинга в стратегическом и текущем планировании охватывает следующие компоненты деятельности организации:

- использование оборудования и обновление материально-технической базы; 
- маркетинг;

- финансовая деятельность, включая управление ресурсами предприятия на финансовом рынке;

- производство, технологии;

- инновации, их создание или приобретение и внедрение в производство;

- управление компетенциями персонала, повышение профессиональной квалификации;

- управление ресурсами, оптимизация производственных запасов.

Схема взаимосвязи стратегических и текущих задач предприятия с учетом рассмотренных областей применения контроллинга приведена на рис. 2

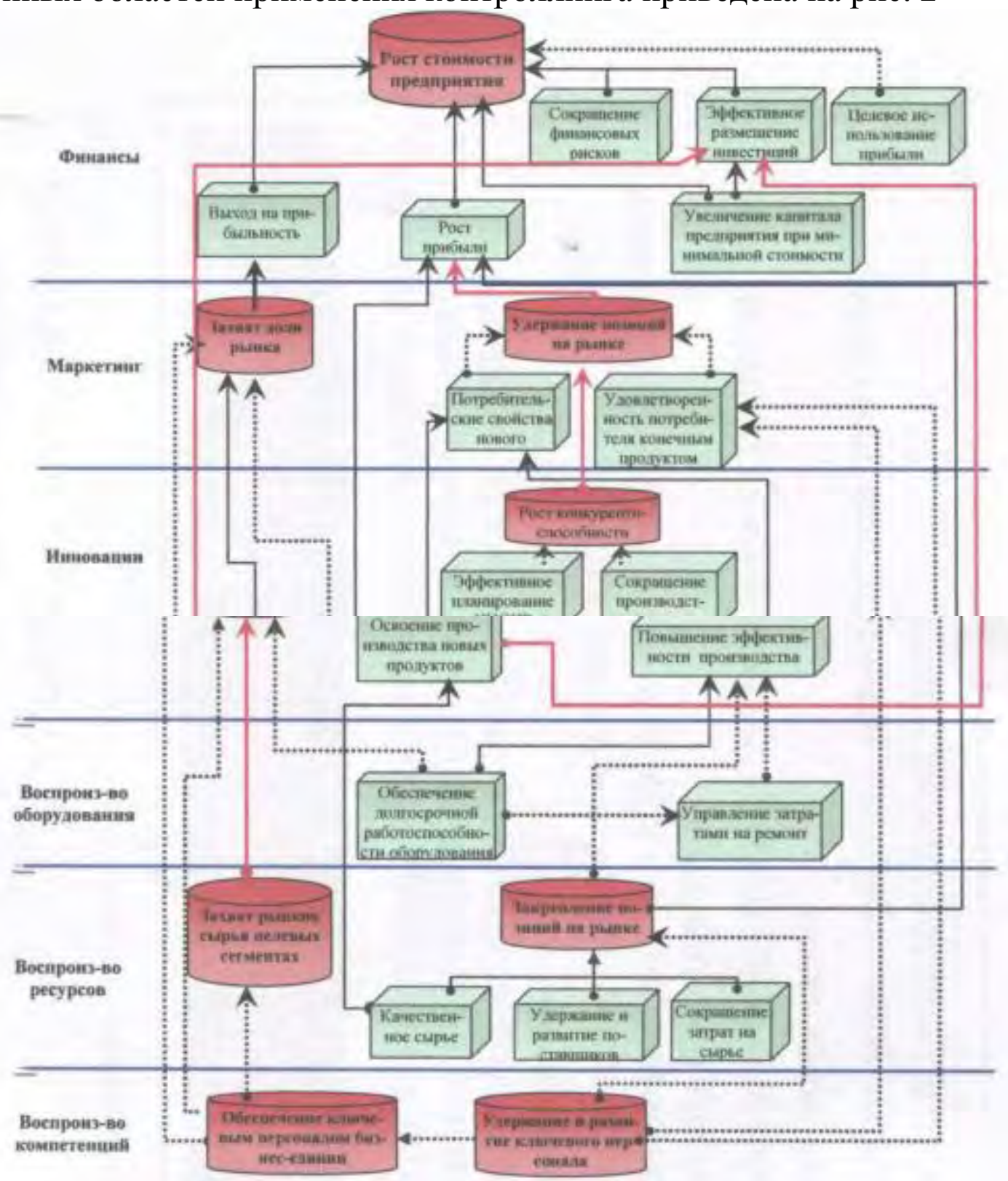

Рис. 2 - Схема взаимосвязи стратегических и текущих задач предприятия. 
Система взаимосвязи текущего и пост-фактум контроля включает в себя:

1. Элементы текущего контроля:

- установление контролируемых показателей и контрольных точек (временных периодов, этапов технологического процесса и т.д.);

- измерение результатов деятельности предприятия с получением определенных значений контролируемых показателей в контрольных точках процессов в ходе их выполнения;

- определение характера и величины потенциальных отклонений.

2. Элементы пост-фактум контроля

- получение фактических данных результатов реализации процессов.

- определение величины произошедших отклонений.

3. Сравнительный анализ плановых и фактических измеряемых показателей реализации производственных и бизнес-процессов предприятия.

4. Определение величины отклонений фактических показателей от плановых и определение степени влияния отклонений на качество производства и эффективность бизнес-процессов.

5. Разработка мероприятий по ликвидации отклонений деятельности по измеряемым показателям которая может включать в себя, как мероприятия по улучшению деятельности, так и корректировку планов.

6. Принятие управленческих решений и их реализация.

При этом следует отметить, что система контрольных показателей, с точки зрения системы менеджмента качества должна включать в себя:

- показатели, характеризующие основные качественные характеристики производимой продукции, коррелирующие с предпочтениями и интересами потребителей;

- количественные показатели производства и его отдельных этапов;

- показатели, оценивающие коммуникацию предприятия с внешней средой и корпоративную коммуникативную систему, включая показатели, оценивающие качество исполнения решений, переданных в устной или письменной форме работникам предприятия, скорость документооборота, скорость внедрения инновационных предложений, полученных менеджментом предприятия от работников, уровень доверия в организации с учетом организационной иерархии, групповых систем предприятия и слабоорганизованных сообществ внутри предприятия;

- показатели, оценивающие качество сервиса, включая и нформационноконсультационное обеспечение, предпродажную подготовку и послепродажное обслуживание клиентов. 


\section{ВЫВОДЫ}

Концепция развития производственного контроллинга ориентирована на экономическую безопасность и устойчивость современных промышленных предприятий РФ за счет снижения затрат и повышения эффективности деятельности предприятия, оптимального распределения оборотных активов, обеспечения слаженности системы первичного документооборота и оперативности получения фактической информации о текущей деятельности подразделений и предприятия в целом; оптимизации системы внутренней (управленческой) отчетности [2].

\section{ЛИТЕРАТУРА}

1. Гайдель, И. История становления органов управления образованием [эл.ресурс] / Сайт: «Образование в России для иностранных граждан». Режим доступа: http://www.russia.edu.ru/edu/description/history_edu /965/ - Загл. с экрана.

2. Шатилова В.П. Динамика изменения инфраструктуры научноисследовательской деятельности в российских университетах XIX века [эл.ресурс] / научный педагогический и психолого-педагогический журнал «Человек и образование». № 1.- 2012. Режим доступа: http://obrazovanie21.narod.ru/files/2012-1_p151-156.pdf

3. Регламент Московской гимназии [эл.ресурс] / по тексту копии, находящейся в ЦГАДА, p. XVII, д. 38, лл. 28 - 42. Режим доступа: http://febweb.ru/feb/lomonos/critics/other/bel/bel-293-.htm

4. Кризис европейских университетов на рубеже XVIII-XIX веков и создание университетской системы в России [эл.ресурс] / Режим доступа: http://www.razlib.ru/istorija/rossiiskie_universitety_xviii_pervoi_poloviny_xix_veka _v_kontekste_universitetskoi_istorii_evropy/p4.php

5. $\overline{\mathrm{O}}$ французском университете [эл.ресурс] / Журнал Министерства народного просвещения. Режим доступа: http://ru.wikisource.org

6. Rüegg, «Themes», A History of the University in Europe, Vol. III, p.5-6

7. Quoted in Christopher Clark, Iron Kingdom: The Rise and Downfall of Prussia, $1600-1947$, p. 333 